\title{
Assessment of Left Ventricular Function in Secundum Atrial Septal Defect: Evaluation by Determination of Volume, Pressure, and External Systolic Time Indices
}

\author{
AARON R. LEVIN, ${ }^{(41)}$ PHILIP R. LIEBSON, KATHRYN H. EHLERS, AND BERNARD DIAMANT \\ Departments of Pediatrics and Medicine, New York Hospital-Cornell University Medical Center, New York, New York, USA
}

Extract

Left ventricular function and volume data from 17 control subjects and 27 young patients with secundum atrial septal defect (ASD) without overt left or right ventricular failure were compared. ASD patients were subdivided in low shunt $(\mathrm{Qp} / \mathrm{Qs}<\mathbf{2 . 0})$ and high shunt $(Q p / Q s \geq 2.0)$ groups. Mean left ventricular ( $L V)$ stroke volume was significantly less in ASD patients $\left(46 \pm 16 \mathrm{ml} / \mathrm{m}^{2}\right.$ in the low shunt and $44 \pm 9 \mathrm{ml} / \mathrm{m}^{2}$ in high shunt group) compared with control patients $\left(51 \pm 13 \mathrm{ml} / \mathrm{m}^{2}, P<0.01\right.$ and $P<0.02$, respectively). There was no significant difference in mean left ventricular end-diastolic volume ( $L V E D V$ ) between any group of patients (control subjects $67 \pm 17 \mathrm{ml} / \mathrm{m}^{2}$; low shunt ASD $66 \pm 17$ $\mathrm{ml} / \mathrm{m}^{2}$, and high shunt ASD $\left.62 \pm 12 \mathrm{ml} / \mathrm{m}^{2}\right)$. High shunt ASD had a significantly lower cardiac index compared with control patients (5.0 liters $/ \mathrm{min} / \mathrm{m}^{2}$ vs. 5.9 liters $/ \mathrm{min} / \mathrm{m}^{2}, P<\mathbf{0 . 0 2}$ ). Both low shunt and high shunt ASD showed significantly lower stroke work indices than control subjects $\left(42 \pm 13 \mathrm{GmM} / \mathrm{m}^{2}\right.$ and $37 \pm 8 \mathrm{GmM} / \mathrm{m}^{2}$ compared with $51 \pm 14 \mathrm{GmM} / \mathrm{m}^{2}, P<0.05$ and $P<0.001$, respectively) but only the high shunt group had a significantly lower peak systolic pressure $(94 \pm 12 \mathrm{~mm} \mathrm{Hg}$ vs. $109 \pm 11 \mathrm{~mm} \mathrm{Hg}$ for control patients, $P<0.01$ ). There was no significant difference between the control and ASD groups in LV end-diastolic, mean right atrial, right ventricular end-diastolic, and pulmonary pressures.

External systolic time intervals were compared in 5 control and 12 ASD patients. There was no significant difference between the two groups of patients in absolute values or indices for pre-ejection period, ejection time, or electromechanical systole. However, the ratio of the pre-ejection period index to left ventricular ejection time index (PEPI/LVETI) was significantly higher in ASD patients $(P$ $<0.05$ ).

In young subjects with large shunt ASD, certain indicators of left ventricular function are depressed. Evaluation of PEPI/LVETI may allow noninvasive determination of $\mathrm{LV}$ function.

\section{Speculation}

Previous studies have shown that left ventricular failure may occur in adults with right ventricular volume overload. The finding of left ventricular dysfunction in children with right ventricular volume overload because of atrial septal defect would confirm the relationship between right ventricular volume overload and secondary functional changes occurring in the left ventricle. Such changes in left ventricular function may be primary or due to alterations in left ventricular geometry because of increased right ventricular enlargement.

In recent years, both clinical and animal studies have suggested a relationship between disorders of the right ventricle with myocardial hypertrophy and left ventricular dysfunction $(5,19,24)$. Atrial septal defect, which results in right ventricular volume overload (6), should not affect left ventricular function since there is neither abnormal left ventricular afterload nor an increase in left ventricular volume. However, evidence of left ventricular dysfunction has been reported in adults when atrial septal defect has resulted in severe right ventricular overload or failure (10).

In order to explore the relationship between right ventricular volume overload and secondary functional abnormality of the left ventricle, we have studied a young population with secundum atrial septal defect to determine whether subtle left ventricular dysfunction may be present in patients without overt right or left ventricular failure. Angiographic parameters, direct pressure measurements, and externally recorded systolic time intervals obtained in these young subjects have been compared with those of a group of similarly aged persons with normal data. These data suggest that asymptomatic young individuals with large left-to-right shunts due to secundum atrial septal defect exhibit abnormal parameters of left ventricular function.

\section{METHODOLOGY \\ PATIENT POPULATION}

Data were collected on 44 patients aged 3-23 years, undergoing routine diagnostic cardiac catheterization under local anesthesia. Patients were divided into two categories.

Group I. This group included 17 normal control subjects who were shown at catheterization to have insignificant lesions and normal cardiac function. All these patients demonstrated normal heart size on conventional cardiac series of chest roentgenograms. Their diagnoses included innocent systolic murmurs, mild pulmonary valvular stenosis (transvalvular gradient less than $25 \mathrm{~mm} \mathrm{Hg}$ ), mild peripheral pulmonary stenosis, and aortic arch abnormalities without obstruction or abnormal electrocardiographic tracings with normal cardiac catheterization findings. This group consisted of 7 males and 10 females with mean age of $9 \pm 4$ years and mean body surface area (2) of $1.04 \pm 0.30 \mathrm{~m}^{2}$ (Table 1).

Group II. This group included 27 patients with isolated secundum ASD studied electively and consecutively. In each patient, associated abnormalities such as partial anomalous pulmonary venous return, mitral regurgitation, systolic ballooning or prolapse of mitral valve, and left ventricular anomalies were excluded. The diagnosis was established by hemodynamic and oxygen saturation data, hydrogen gas dilution studies, dye dilution curves, and angiocardiography. Additional confirmation in the majority was obtained at open heart surgery. Patients with ASD were subdivided into two subgroups on the basis of shunt size (Table 1). Subgroup IIA (low shunt group) consisted of 12 patients in whom the pulmonary-to-systemic flow ratio was less than 2.0; there were 5 males and 6 females. Mean age was $8 \pm 5$ years and body surface area was $0.93 \pm 0.40 \mathrm{~m}^{2}$. Subgroup IIB (high shunt group) included 16 patients with pulmonary-to-systemic flow ratios of 2.0 or greater; 7 were males and 9 females. Mean age was $7 \pm 5$ years and body surface area was $0.85 \pm 0.25 \mathrm{~m}^{2}$. None of the patients in either subgroup were in congestive heart failure and all had a pulmonary-to-systemic resistance ratio below 0.3 .

There was no significant difference in mean age between any of 
the groups. Body surface area was lower in the high shunt ASD subgroup than the control but this was not statistically significant. Mean heart rates during angiography were no different in any of the groups, being $109 \pm 22$ for the controls, $110 \pm 20$ for the low shunt ASD group, and $113 \pm 19$ for the high shunt ASD group.

Mean values for each indicator of left ventricular function obtained at cardiac catheterization with contrast visualization were determined for each group of patients. The values for ASD were compared with those obtained in control patients and significance of differences statistically determined utilizing the two-tailed $t$-test and an Olivetti Programma 101 computer (7).

\section{DATA ACQUISITION}

All patients were studied in the supine position after sedation with meperidine $(1.0 \mathrm{mg} / \mathrm{kg})$, chlorpromazine $(0.25 \mathrm{mg} / \mathrm{kg})$, and promethazine $(0.25 \mathrm{mg} / \mathrm{kg}$.) Pressure measurements were obtained in the left ventricle utilizing no. 6 or no 7 catheters with lateral holes and sealed ends and left ventriculography was performed with these catheters or after substitution with pigtail catheters (34). The first angiocardiogram was performed in the left ventricle and pressure recordings in this chamber were made just before the injection of contrast medium. The pressure recording system included Statham P23Db pressure transducers, referenced to a point midway between the table top and the sternum, and an Electronics for Medicine pressure amplifier (model SGM 2). The system had an impulse transmission time varying between 10 and $20 \mathrm{msec}$.

Left ventricular volume data were determined after biplane left ventricular angiocardiography in the AP and lateral projections using $75 \%$ Hypaque $(35)(1.0 \mathrm{ml} / \mathrm{kg})$ injected at a rate of $16-20$ $\mathrm{ml} / \mathrm{sec}$. The filming was programmed for 6 frames/sec. Calculations of end-diastolic and end-systolic volumes were obtained utilizing the area-length method of Dodge et al. $(8,9,14)$ in the absence of ectopic beats or a change in the preinjection heart rate. In those showing ectopic beats measurements of the ventricle were made when adequate visualization was obtained with the second beat after the premature beats. Ectopic beats occurred during ventriculography in five control patients $(26 \%)$, six with small shunt ASD (50\%), and in five with large shunt ASD (31\%). A minimum of two beats was usually available for calculation of volume. The electrocardiogram was monitored throughout the angiocardiogram and recorded at a paper speed of $100 \mathrm{~mm} / \mathrm{sec}$. Each exposure was recorded by an electronic device so that it could be localized to a specific period of the cardiac cycle by reference to the simultaneously recorded electrocardiogram. After each study, a metal grid with 1 -inch squares was placed parallel to the AP and then to the lateral $x$-ray tubes, at the same position occupied by the left ventricle during angiocardiography. The film of the grid was used to correct for x-ray magnification. No adjustments were made for inherent image tube distortion. Left ventricular stroke volume (LVSV) was obtained by subtracting the left ventricular end-systolic volume (LVESV) from the end-diastolic volume (LVEDV). The ejection fraction (EF) was derived by dividing the LVSV by LVEDV. Left ventricular stroke (LVSW) was determined from the standard formula: $\mathrm{LVSW}=0.0136 \times \mathrm{LV} \overline{\mathrm{m}} \times$ LVSV, where $L V \bar{m}$ represented left ventricular mean systolic pressure and LVSV the left ventricular stroke volume corrected for body surface area.

\section{CALCULATION OF HEMODYNAMIC DATA}

Left-to-right shunts at atrial level were confirmed by the hydrogen gas dilution technique (28) and dye dilution technique (33), as well as by sequential oxygen saturation data and angiocardiography $(27,29)$. Systemic (Qs) and pulmonary (Qp) blood flows were calculated from standard formulas with samples drawn in rapid succession from the pulmonary artery and superior and inferior vena cavae, while arterial blood was sampled simultaneously from the left ventricle or ascending aorta. Where only one catheter was utilized with the venous approach, samples were drawn in rapid succession from the right heart sites, and then from a pulmonary vein or left atrium. Oxygen saturation data from these sites were derived from measurement of oxygen tension utilizing an Instrumentation Laboratories $113 \mathrm{pH}, \mathrm{pO}_{2}$, and $\mathrm{pCO}_{2}$ meter and the Severinghaus nomogram to correct for $\mathrm{pH}$ and temperature. Expired gas was collected in a Tissot tank for a 3-min period and analyzed for oxygen content utilizing a Scholander gas analyzer. In order not to disturb patients who were sedated. collections were made in all subjects at the end of the diagnostic procedure before removal of catheters so that simultaneous blood samples could be drawn. In those younger patients in whom expired gas could not be collected, oxygen consumption was assumed from the data of Rudolph and Cayler (27, 29). The calculation of pulmonary-to-systemic flow ratio $(\mathrm{Qp} / \mathrm{Qs})$ was derived from the division of pulmonary flow by systemic flow. Pulmonary and systemic resistance values and their ratios were derived from standard formulas (29).

\section{ACQUISITION OF INDIRECT LEFT VENTRICULAR SYSTOLIC INTERVALS}

At least $30 \mathrm{~min}$ after the last angiocardiogram (3), and no more than $90 \mathrm{~min}$ thereafter, indirect systolic time intervals (STI) were obtained using simultaneous recordings of heart sounds, indirect carotid pulse tracing, and electrocardiogram (Fig. 1). Simultaneous recordings of left ventricular pressure were obtained. These parameters were recorded in 5 normal patients and 12 with ASD: the age range for those studied was 3-23 years. Recordings were made using an Elema-Schonander Mingograf 34 four-channel ink jet recorder (36) at a paper speed of $100 \mathrm{~mm} / \mathrm{sec}$ with time lines equivalent to $10 \mathrm{msec}$. In all cases, the patient was supine with head extended and the neck elevated about $30^{\circ}$ from the horizontal position. All studies were performed between 9 and 11:30 AM. Heart sounds were recorded from the precordial area which would result in the most discrete recording of $\mathrm{S}_{2}$, usually the left sternal border in the 2 nd intercostal space. The peak frequency recorded was $100 \mathrm{~Hz}(50 \%$ attenuated at 50 and $200 \mathrm{~Hz})$. A piezoelectric disc microphone was used (EMT 25B). Carotid pulse was recorded using a piezoelectric crystal transducer with Marey's capsule applied manually to the neck (EMT 510C transducer).

The following time intervals were evaluated and expressed in milliseconds: total electromechanical systole $\left(Q-S_{2}\right)$; left ventricular ejection time (LVET); and pre-ejection period (PEP). PEP/LVET ratio was obtained from these determinations $(30,31)$ (Fig. 1). Correction of actual measured intervals of $\mathrm{Q}-\mathrm{S}_{2}, \mathrm{LVET}$, and PEP was made for age and heart rate according to the regression equation of Golde and Burstin $(12,22)$, thus producing indices for Q-S ${ }_{2}$, LVET, and PEP (Q-S ${ }_{2}$, LVETI, PEPI). PEP/LVET ratio results were determined from the actual values measured, and from the corrected indices (PEPI/LVETI). The correlation of external and internal indices of left ventricular ejection time and pre-ejection phase has been previously demonstrated by others $(11,23)$.

Statistical analysis of results, using the two-tailed $t$-test (7), was accomplished with an Olivetti Programma 101 computer. All mean values in this report are recorded with $\pm 1 \mathrm{SD}$.

\section{RESULTS}

\section{ANGIOGRAPHICALLY DETERMINED DATA}

Mean values for left ventricular volume and function data for individual patients in each group are displayed in Table 1. Mean left ventricular end-diastolic and end-systolic volume indices were not significantly different in the ASD patients compared with control subjects. Left ventricular stroke-volume indices were lower than contol subjects in both groups of ASD patients but the difference was not statistically significant. The ejection fraction was significantly decreased $(P<0.01)$ in the low shunt ASD group $(0.68 \pm 0.06)$ compared with control subjects $(0.75 \pm 0.05)$ (Table 
1). The high shunt ASD group also had a decreased ejection fraction $(0.70 \pm 0.07)$ when compared with control subjects $(P<$ $0.02)$.

\section{HEMODYNAMIC DATA}

Mean values for hemodynamic data for patients in each group are presented in Table 1. Left ventricular peak systolic pressure was significantly decreased $(P<0.01)$ in the high shunt ASD group $(94 \pm 12 \mathrm{~mm} \mathrm{Hg}$ ) compared with control subjects ( $109 \pm 11$ $\mathrm{mm} \mathrm{Hg}$ ). Mean left ventricular pressure reflected this, being lower in the high shunt ASD group ( $63 \pm 8 \mathrm{~mm} \mathrm{Hg}$ ) than in the control patients $(72 \pm 10 \mathrm{~mm} \mathrm{Hg}, P<0.01)$. Mean left ventricular end-diastolic pressure was not different in any of the groups; end-diastolic pressure ranged from 2 to $12 \mathrm{~mm} \mathrm{Hg}$ in control subjects, whereas in the low shunt ASD group, the range was 2-15 $\mathrm{mm} \mathrm{Hg}$ with two patients exhibiting pressures above $12 \mathrm{~mm} \mathrm{Hg}$. In the high shunt ASD group, LVEDP ranged from 6 to $13 \mathrm{~mm} \mathrm{Hg}$ with one patient displaying a pressure above $12 \mathrm{~mm} \mathrm{Hg}$. Left ventricular stroke work index (SWI) in the low shunt and in the high shunt ASD groups were $42 \pm 13$ and $37 \pm 8$ gm (gram meters) $/ \mathrm{m}^{2}$ respectively, compared with the control mean of $51 \pm$ $14 \mathrm{gm} / \mathrm{m}^{2}(P<0.05$ and $P<0.001)$. Comparison of SWI and LVEDP in each group showed no correlation between these two parameters. Cardiac index (Fick) was $5.0 \pm 0.9$ liters $/ \mathrm{min} / \mathrm{m}^{2}$ in the high shunt ASD group and $5.9 \pm 1.1$ liters $/ \mathrm{min} / \mathrm{m}^{2}$ in control patients $(P<0.02)$. Systemic peripheral resistance was not significantly different in either ASD group.

None of the right-sided pressures in any ASD group showed significant differences from control mean values. Right atrial mean pressures ranged from 1 to $10 \mathrm{~mm} \mathrm{Hg}$ in control patients. Only one patient in the low shunt ASD group had a pressure above $10 \mathrm{~mm} \mathrm{Hg}$, whereas none of the high shunt group displayed elevation of right atrial mean pressure. Right ventricular systolic pressure ranged between 18 and $39 \mathrm{~mm} \mathrm{Hg}$ in the control group and end-diastolic pressures from 0 to $12 \mathrm{~mm} \mathrm{Hg}$. The low shunt ASD group had a right ventricular systolic pressure ranging from 21 to $40 \mathrm{~mm} \mathrm{Hg}$ and all end-diastolic pressures were $7 \mathrm{~mm} \mathrm{Hg}$ or less. In the high shunt ASD group, right ventricular systolic pressures ranged between 26 and $52 \mathrm{~mm} \mathrm{Hg}$, but none had an end-diastolic pressure above $12 \mathrm{~mm} \mathrm{Hg}$. Pulmonary artery diastolic pressures ranged from 5 to $13 \mathrm{~mm} \mathrm{Hg}$ in the control group. Of the ASD patients, only one in the low shunt group had a diastolic pressure outside this range, being $15 \mathrm{~mm} \mathrm{Hg}$.

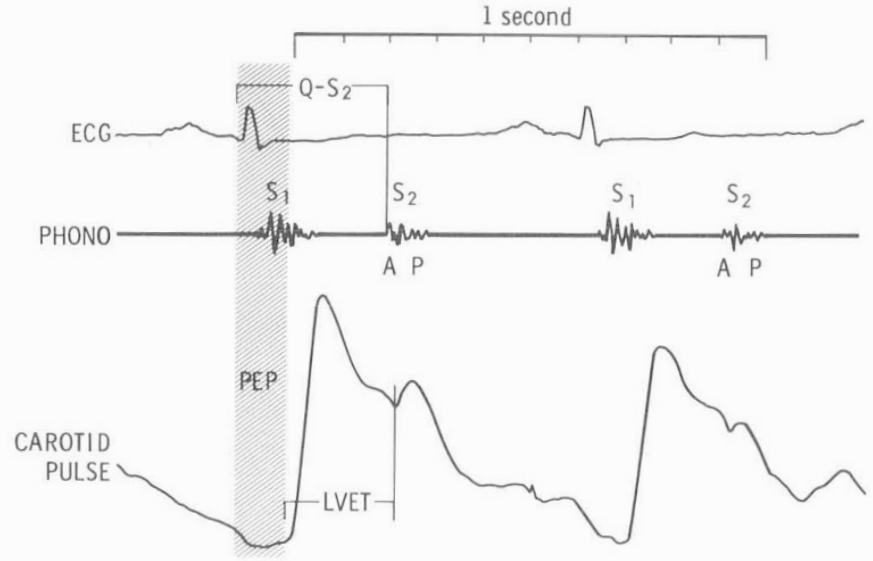

Fig. 1. The absolute values of the systolic time intervals were determined by simultaneous electrocardiogram (ECG) (lead II), phonocardiogram, and external carotid pulse tracing. Tracings were recorded at 100 $\mathrm{mm} / \mathrm{sec}$. Total electromechanical systolic interval $\left(Q-S_{2}\right)$ was measured from the beginning of the QRS complex to the aortic component of the second heart sound. Left ventricular ejection time ( $L V E T)$ was measured from the beginning of the upstroke of the carotid pulse to the incisura. Pre-ejection period $(P E P)$ was derived by subtracting LVET from Q-S $\mathrm{S}_{2}$.

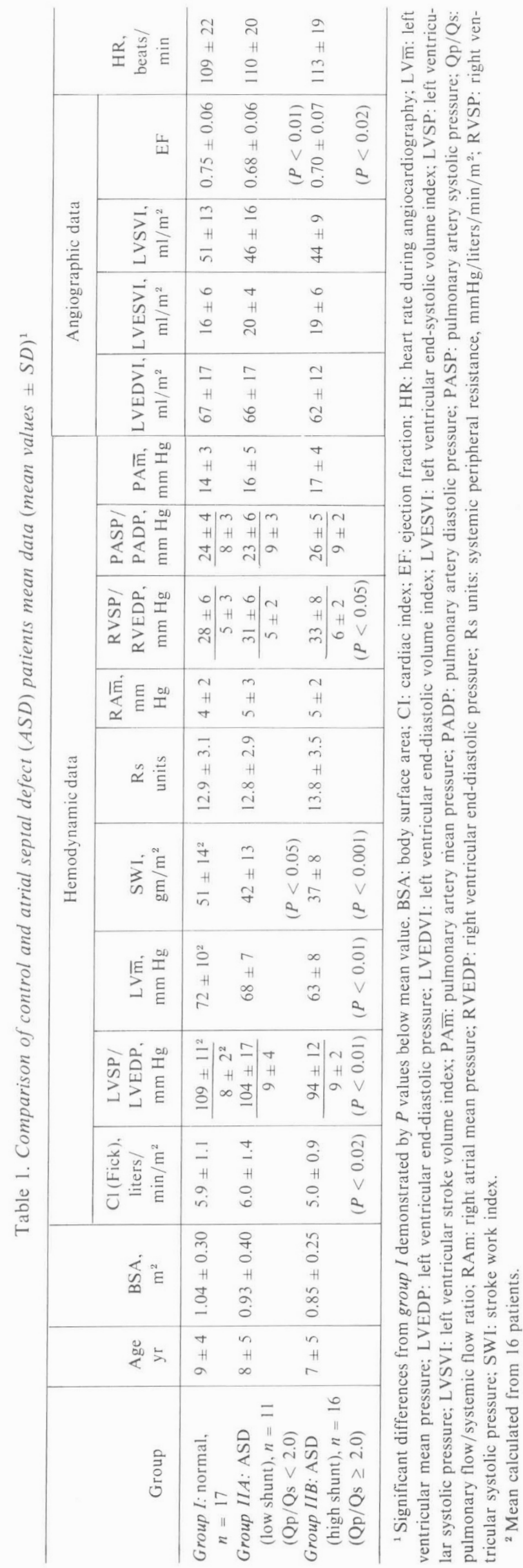




\section{EXTERNAL SYSTOLIC TIME INTERVALS}

Seventeen of the catheterized patients were evaluated by the techniques of indirect systolic time interval determinations at the time of cardiac catheterization. Five of these, in the control group, were compared with 12 patients with atrial septal defects. The pulmonary-to-systemic flow ratios in the latter ranged from 1.2 to $3.9($ mean $=2.55 \pm 0.85)$. Comparisons between the groups are noted in Table 2.

There was no significant difference in age or heart rate between the two groups, although the mean heart rate was slightly lower in the control patients. The higher values in PEPI and $\mathrm{Q}-\mathrm{S}_{2} \mathrm{I}$ in the ASD group compared with control subjects were not statistically significant. The difference in LVETI in patients with ASD (350 $19 \mathrm{msec})$ and control subjects $(334 \pm 20 \mathrm{msec})$ was also significantly different. PEPI/LVETI, however, was significantly higher $(P<0.05)$ in the ASD group $(0.286 \pm 0.042)$ than in normal subjects $(0.226 \pm 0.057)$ (Fig. 2)

\section{DISCUSSION}

Previous studies of normal left ventricular function in childhood have shown that angiocardiographically determined left ventricular volume corrected for body surface area is significantly lower in children below 2 years of age compared with older children (14. 15). Therefore, only patients 2 years or older were included in our series. Comparison of our control data with that of normal patients cited in Graham et al. studies $(14,15)$ showed no significant difference in right or left ventricular pressures or left ventricular end-diastolic volume, although left ventricular systolic pressure and ejection fraction were slightly higher in our patients. The latter was reflected in a higher left ventricular clearance. Review of our data and the methods employed in this study reveal no apparent reason for the larger left ventricular ejection fraction compared with those recorded by others (14, 15). Although cineangiography at 60 frames/sec and exposure every $16.6 \mathrm{msec}$. as employed by Graham et al. (14, 15) should permit more accurate localization of end systole and end diastole, angiocardiography with 6 frames/sec and exposures every 166 msec has been successfully employed by other workers in both children and adults to delineate left ventricular events $(4,8,9,16,18,20,25,26)$. Failure to accurately note the times of end systole and end diastole angiographically would tend to reduce the ejection fraction rather than to increase it. Furthermore, these periods of the cardiac cycle were localized electronically by relating the angiographic exposures of the left ventricle to the simultaneously recorded electrocardiogram while those associated with premature ventricular contractions were excluded from analysis.. Whatever the factors, if any, influencing our values for ejection fraction, these should be the same for all patient groups, and although they do not agree with those of others, this should not invalidate the interpatient and intergroup comparison of this study.

All patients in the ASD group had isolated ostium secundum defects without anomalously draining pulmonary veins, mitral regurgitation, or ballooning or prolapsing mitral valve or left ventricular anomalies, or elevation of pulmonary vascular resistance. Thus, the load placed on the right ventricle was purely a volume load, and any effects upon left ventricular performance might be due to a decrease in left ventricular preload, increase in left ventricular after load, or to secondary effects upon the left ventricle produced by abnormalities of right ventricle geometry or a primary abnormality of the left ventricle.

Careful attention was paid to recording indirect indices as close to the time of angiocardiography as possible, and to account for age, time of day, and patient population. All of these factors have been shown to affect the systolic time indices $(12,22)$. Patients with heart rates above 125 beats/min during recordings of STI were excluded in our final analysis because of possible variations in the linearity of regression lines of time indices at higher heart rates. Evaluation of systolic time indices must also be related to medications (32). None of our patients was receiving digitalis and the only medication given was precatheterization sedation which was uniform in all patients. The effect of cardiac catheterization on $\mathrm{PEP} /$ LVET ratio must also be considered since our studies were performed under those circumstances. Weissler et al. (32) demonstrated that, compared with basal values. PEP/LVET does not vary significantly when catheterization is performed and the mean systolic time indices for our control patients were close to those of Golde and Burstin (12) in children.

PEP/LVET ratio has been determined in most studies by using the actual values for each systolic time interval to derive the ratio. We have determined both PEP/LVET and PEPI/LVETI, the latter ratio being derived from the actual systolic time intervals corrected for age and heart rate, since Golde and Burstin (12) have shown that PEP and LVET normally vary with age for a specific heart rate in children. Thus, using derived intervals for determining the ratio (PEPI/LVETI) and therefore accounting for age, may permit a more valid result.

Cardiac index determinations reveal somewhat higher control values for our laboratory when compared to those obtained by others (27), and may be related to expired gas collections and blood sampling for determination of oxygen consumption and cardiac output being made at the end of the diagnostic study. This standard procedure was adopted for all patients in whom expired gas collections were made to diminish disturbance of these sedated young subjects and to maintain as steady a state as possible during data acquisition.

Our data demonstrate that in young patients with atrial septal defect, and especially those with large left-to-right shunts (Qp/Qs $\geq 2.0$ ), there are decreases in systemic cardiac index, left ventricular ejection fraction, stroke work, and left ventricular systolic and mean pressure when compared with control patients of similar age. These differences cannot be attributed to significantly lower left ventricular end-diastolic volume or end-diastolic pressure in our patients with atrial septal defect, nor to increase in left ventricular afterload. Others have found abnormalities of left ventricular function in patients with ASD. Flamm et al. (10) demonstrated decreased systemic cardiac output, associated with low left ventricular filling pressure. Levinson et al. (21) demon-

Table 2. Mean left ventricular indirect systolic time intervals (mean values $\pm I S D)^{1}$

\begin{tabular}{|c|c|c|c|c|c|c|c|c|c|c|c|}
\hline \multirow[b]{2}{*}{ Group } & \multirow{2}{*}{$\begin{array}{c}\text { Age, } \\
\text { yr }\end{array}$} & \multirow[b]{2}{*}{ Qp/Qs } & \multicolumn{6}{|c|}{$\mathrm{msec}$} & \multirow[b]{2}{*}{ HR } & \multirow[b]{2}{*}{ PEP/LVET } & \multirow[b]{2}{*}{ PEPI/LVETI } \\
\hline & & & LVET & LVETI & PEP & PEPI & Q-S ${ }_{2}$ & Q-S $\mathrm{S}_{2}$ & & & \\
\hline Group I: controls $(n=5)$ & $10 \pm 4$ & 1.0 & $256 \pm 40$ & $335 \pm 20$ & $88 \pm 25$ & $82 \pm 19$ & $344 \pm 53$ & $416 \pm 13$ & $88 \pm 14$ & $0.347 \pm 0.089$ & $0.226 \pm 0.057$ \\
\hline Group II: $\operatorname{ASD}(n=12)$ & $8 \pm 7$ & $2.55 \pm 0.85$ & $241 \pm 28$ & $350 \pm 19$ & $92 \pm 15$ & $100 \pm 14$ & $333 \pm 35$ & $433 \pm 60$ & $102 \pm 15$ & $0.386 \pm 0.071$ & $0.286 \pm 0.040$ \\
\hline Significant differences ${ }^{2}$ & NS & & NS & NS & NS & NS & NS & NS & NS & NS & $\mathrm{p}<0.05$ \\
\hline
\end{tabular}

${ }^{1}$ HR: heart rate; LVET: left ventricular ejection time; LVETI: left ventricular ejection time index; NS: not significant; PEP: pre-ejection period; PEPI: pre-ejection period index; $Q-S_{2}$ : electromechanical systole: $Q-S_{2} I$ : electromechanical systole index; Qp/Qs: pulmonary flow/systemic flow ratio; ASD: atrial septal defect.

${ }^{2}$ Significant differences between groups indicated by $P$ value below mean value. 




Fig. 2. Comparison of ratio of pre-ejection period index to left ventricular ejection time index (PEPI/LVETI) ratio in 5 control and 12 atrial septal defect $(A S D)$ patients. PEPI/LVETI was significantly increased in the ASD group $(P<0.05)$.

strated a decreased left ventricular end-diastolic volume, which would support the concept of lower cardiac output on the basis of decreased volume preload to the left ventricle. Graham et al. (13 have also shown abnormalities of left ventricular function in children and atrial septal defect with large left-to-right shunts: these included low left ventricular end-diastolic volume and low left ventricular systolic output, but a normal ejection fraction. Our findings are in concurrence with others in that a lower cardiac output is demonstrated in the high shunt ASD group. However, on the basis of our studies, we have found no evidence to suggest that left ventricular preload, as demonstrated by end-diastolic volume or pressure, is diminished. Nor have we been able to demonstrate any significant difference in left ventricular afterload in the various patient groups to account for the differences in the parameters of left ventricular function measured: evaluation of the systemic peripheral resistance in each group analyzed was not significantly different.

Increases in right ventricular preload within the physiologic range has been shown by Kelly et al. (19) to shift the pressurevolume curve of the left ventricle so that a given left ventricular volume may be associated with a higher left ventricular pressure. In their animal studies they suggest that the shift may be because of alterations in left ventricular geometry or to secondary changes in the left ventricle because of right ventricular stress. These changes may possibly be caused by metabolic alterations in the right ventricle. Furthermore, left ventricular end-diastolic pressure may not reflect subtle abnormalities of left ventricular function. Thus, abnormalities of the left ventricular contractility, as measured by peak $\mathrm{dP} / \mathrm{dt}$, peak velocity of contractile element shortening at peak left ventricular wall stress may be associated with little change in left ventricular end-diastolic pressure. Our studies did not evaluate indices of contractility per se, and it is possible that the normal left ventricular end-diastolic pressure noted in our ASD group have masked a similar abnormality in contractility.

Studies using external systolic time intervals have shown that left ventricular performance abnormalities are associated with increases in PEP. decreases in LVET, and resultant increases in PEP/LVET ratio $(30,31)$. Although the PEP/LVET ratio in the ASD patients was not significantly different from the control group, we have demonstrated an increased PEPI/LVETI ratio. This finding suggests left ventricular dysfunction, although most marked rises in PEPI/LVETI ratio have been found only in patients with an obviously decompensated left ventricle. This further indicates that, in pediatric patients, the ratio of the indices for PEP and LVET might be more sensitive than derivation from the actual times measured. Failure to demonstrate an abnormal LVET in our series may be because of the many factors affecting this interval. LVET has been shown to correlate with stroke volume, end-diastolic volume, ejection fraction, and left ventricu- lar end-diastolic pressure (11), and abnormalities in contractility appear to correlate better with increased PEP duration (1, 17). Ahmed et al. (1) found this to be the case in an evaluation of the relation between systolic time intervals and measures of left ventricular contractility. In their study, patients with right ventricular overload showed an insignificant elevation in PEP/LVET ratio. After decreased diastolic filling. PEP may be prolonged and LVET may be diminished, thereby increasing PEP/LVET ratio. This cannot explain our findings, however, since left ventricular end-diastolic volumes were not different in our ASD and control patients. Ahmed et al. (1) also demonstrated that subnormal ejection fraction, stroke volume, and cardiac index may not be related to abnormal left ventricular contractility as determined by such measurements as velocity of contractile element at peak $\mathrm{dP} / \mathrm{d}$ : they did, however, correlate well with PEP/LVET. Therefore, our finding of elevated PEPI/LVETI in the ASD group of patients may strengthen the possibility of subtle abnormalities of contractility in these patients, and enhance the significance of the decreased stroke work and cardiac output in the high shunt ASD group.

In conclusion, our studies have shown that in pediatric ASD patients with large left-to-right shunts, but without obvious right ventricular failure and pulmonary hypertension, certain indicators of left ventricular function are decreased: indirect assessment of left ventricular function demonstrate abnormalities; and evaluation of PEPI/LVETI ratio may reasonably reflect left ventricular ejection fraction and possibly allow useful noninvasive determination of left ventricular function.

\section{SUMMARY}

Hemodynamic and left ventricular volume data and indirect left ventricular systolic time intervals from 17 control and 26 young patients with isolated secundum ASD without overt left or right ventricular faiure were compared. ASD patients were divided into low shunt $(\mathrm{Qp} / \mathrm{Qs}<2.0)$ and high shunt $(\mathrm{Qp} / \mathrm{Qs} \geq 2.0)$ groups. Compared with controls, both groups of ASD patients were shown to have significantly lower left ventricular stroke volume and stroke work indices. Only high shunt ASD patients displayed a significantly lower cardiac index and left ventricular peak systolic pressure. No difference was noted in the end-diastolic volume in any of the groups, and there was no significant difference between control subjects and ASD patients in left ventricular end-diastolic. mean right atrial, right ventricular end-diastolic, and pulmonary artery pressures. Comparison of left ventricular indirect systolic time intervals in 5 control and 12 ASD patients revealed a significantly higher PEPI/LVETI ratio in the patients with ASD. We conclude that in young subjects with ASD and large left-toright shunts certain indicators of left ventricular function are depressed, and that PEPI/LVETI ratio may allow noninvasive determination of left ventricular function.

\section{REFERENCES AND NOTES}

1. Ahmed, S. S.. Levinson, G. E., Schwartz, C. J., and Ettinger, P. O.: Systolic time intervals as measures of the contractile state of the left ventricular myocardiun in man. Circulation, 46:559 (1972).

2. Boothby, W M and Sandiford, L. Normal values of basal or standard metabolism: A modification of the DuBois standards. Amer. J. Physiol.. 90: 290 (1929)

3. Brown, A. K. Epstein, E. J. Coulshed, N. Clarke, J. M. and Doukas, N. G. Hemodynamic changes after angiography. Brit. Heart J., 31: 233 (1969).

4. Bunnell. I. L.. Grant, C.. and Greene, D. G.: Left ventricular function derived from the pressure-volume diagram. Amer. J. Med., 39: 881 (1965).

5. Chandler, B. M.. Sonnenblock, E. H.. Spann, J. F.. Jr., and Pool, P. E.: Association of depressed myofibrillar adenosine triphosphatase and reduced contractility in experimental heart failure. Circ. Res., 21:717 (1967).

6. Cooley, D. A., Hallman, G. L., and Hammam, A. S.: Congenital cardiovascular anomalies in adults: results of surgical treatment in 167 patients over age 35. Amer. J. Cardiol., 17: 303 (1966).

7. Croxton, F. E.: Elementary Statistics with Applications in Medicine and Biologic Sciences (Dover. New York. 1953).

8. Dodge, H. T Sandler, H. Ballew, D. W and Lord, J. D. Use of biplane angiocardiography for measurement of left ventricular volume in man. Amer Heart J., 60: $762(1960)$ 
9. Dodge. H. T., Sandler, H., Baxley, W. A., and Hawley, R. R.: Usefulness and limitations of radiographic method for determining left ventricular volume. Amer. J. Cardiol., 18: 10 (1966)

10. Flamm, M. D.. Cohn, K. E., and Hancock, E. W.: Ventricular function in atrial septal defect. Amer. J. Med. 48: 286 (1970).

II. Garrard, C. L., Jr.. Weissler, A. M., and Dodge, H. T.: The relationship of alterations in systolic time intervals to ejection fraction in patients with cardiac disease. Circulation, 42: 455 (1970).

12. Golde, D., and Burstin. L.: Systolic phases of the cardiac cycle in children. Circulation, 42: 1029 (1970)

13. Graham, T. P., Jr., Jarmakani, J. M., and Canent, R. V., Jr.: Left heart volume characteristics with a right ventricular volume overload: Total anomalous pulmonary venous connection and large atrial septal defect. Circulation, 45 389 (1972)

14. Graham, T. P., Jarmakani, M. M., Canent, R. V.. Capp, M. P.. and Spach, M. S.: Characterization of left heart volume and mass in normal children and infants with intrinsic myocardial disease. Circulation, 38: 826 (1968).

15. Graham, T. P., Jr., Jarmakani, J. M., Canent, R. V., Jr., and Morrow, M. N. Left heart volume estimation in infancy and childhood: Re-evaluation of methodology and normal values. Circulation, 43: 895 (1971).

16. Hermann, H. J., and Bartle, S. H.: Left ventricular volumes by angiocardiography: comparison of methods and simplification of techniques. Cardiovasc. Res., 4: 404 (1968).

17. Hodges, M.. Halpern, B. L., Friesinger, G. C., and Dagenais, G. R.: Left ventricular pre-ejection period and ejection time in patients with acute myocardial infarction. Circulation, 45: 933 (1972).

18. Judge, T. P., Kennedy, J. W.. Bennet, L. J., Wills, R. E., Murray, J. A., and Blackman, J. R.: Quantitative hemodynamic effects of heart rate in aortic regurgitation. Circulation, 44: 355 (1971).

19. Kelly, D. T. Spotnitz, H. M.. Beiser, G. D.. Pierce, J. E., and Epstein, S. E. Effect of chronic right ventricular volume and pressure loading on left ventricular performance. Circulation, 44: 403 (1971).

20. Kennedy, J. W., Baxley, W. A., Figley, M. M., Dodge, H. T., and Blackman, J. R.: Quantitative angiocardiography. 1. The normal left ventricle in man. Circulation, 34: 272 (1966)

21. Levinson, G. E., Frank, M. J., Nadimi, M., and Braunstein, M.: Studies of cardiopulmonary blood volume: measurement of left ventricular volume by dye dilution. Circulation, 35: 1038 (1967).

22. Lewis, R. P., Boudoulas, H., Forester, W. F., and Weissler, A. M.: Shortening of electromechanical systole as a manifestation of excessive adrenergic stimulation in acute myocardial infarction. Circulation, 46: 856 (1972).
23. Martin. C. E.. Shaver, J. A., Thompson, M. E., Reddy, P. S., and Leonard, J J. Direct correlation of external systolic time intervals with internal indices of left ventricular function in man. Circulation. 44: 419 (1971).

24. Michelson, N.: Bilateral ventricular hypertrophy due to chronic pulmonary disease. Dis. Chest, 38: 435 (1960)

25. Miller, G. A. H. Kirklin, J W. Rahimtoola, S. H and Swan, H. J. C.: Volume of the left ventricle in tetralogy of Fallot. Amer. J. Cardiol.. 16: 488 (1965).

26. Mirsky. I., Pasternac, A., and Ellison, R. C.: General index for the assessment of cardiac function. Amer. J. Cardiol., 30: 483 (1972).

27. Nadas, A. S. and Fyler. D. C.: Pediatric Cardiology, Ed. 3 (W. B. Saunders. Philadelphia, 1972)

28. Rotem, C. E., and Miller. H.: Diagnostic applications of the platinum electrode catheter. Brit. Heart J., 29: 232 (1967)

29 Rudoloh, A, M. and Cayler, G. G. Cardiac catheterization in infants and children. Pediat. Clin. N. Amer. 5: 907 (1958).

30. Weissler, A. M., Harris, W. S., and Schoenfeld, C. D.: Bedside technique for the evaluation of ventricular function in man. Amer. J. Cardiol. 23: 577 (1969).

31. Weissler A M. Peeler. R. G. and Roehll, W H. Relationship between lef ventricular ejection time, stroke volume, and heart rate in normal individuals and patients with cardiovascular disease. Amer. Heart J., 62: 367 (1961)

32. Weissler, A. M. and Schoenfeld, C. D.: Effect of digitalis on systolic time intervals in heart failure. Amer., J. Med. Sci.. 259: 4 (1970).

33. Wood. E. H.: Diagnostic applications of indicator-dilution technics in congenital heart disease. In: Sympsoium on Dye Dilution Techniques. Circ. Res. 10:531 (1962).

34. Cook Co., Inc.

35. Winthrop Laboratories, New York, N. Y

36. Siemens Corp., Iselin, N. J.

37. The authors wish to express their appreciation to Miss Barbara Belfer (New York Hospital-Cornell Medical Center) for her assistance in the accumulation of data and to Mrs. Linda Tartell, Mrs. Shirley Williams, and Mrs. Alice Kramer for their secretarial assistance.

38. Dr. Liebson's present address: Cardiology Division, Rush-Presbyterian-St Luke's Medical Center, Chicago, III

39. Dr. Diamant is deceased.

40. This research was presented in part before the American Academy of Pediatrics October 15, 1972

41. Requests for reprints should be addressed to: Aaron R, Levin, M.D., Pediatric Cardiac Catheterization Laboratory. The New York Hospital-Cornell Medical Center, 525 E. 68 St. New York, N. Y. 10021 (USA)

42. Accepted for publication July 17, 1975
Biopterin

dithioerythritol

hyperphenylalaninemia lysolecithin

phenylalanine hydroxylase

phenylketonuria

\title{
Determination of Phenylalanine Hydroxylase Activity in Patients with Phenylketonuria and Hyperphenylalaninemia
}

\author{
K. BARTHOLOME, (21) P. LUTZ, AND H. BICKEL \\ University Children's Hospital, Heidelberg, Federal Republic of Germany
}

\section{Extract}

The phenylalanine hydroxylase assay was modified by using biopterin, lysolecithin, and dithioerythritol. Liver tissue was obtained by percutaneous needle biopsies in patients with phenylketonuria (PKU) and hyperphenylalaninemia. The use of the naturally occurring cofactor biopterin is essential to measure low enzyme activities. Thirteen of 14 assay specimens in which no activity was detectable correlated with the clinical picture of classic PKU. Twelve assay specimens showed a residual activity up to $6 \%$ of normal. This group comprises patients with classic PKU and with so-called hyperphenylalaninemia. Four specimens ranged between
8.7 and $34.5 \%$ of the normal values. Patients in this group have developed normally so far without dietary treatment. It seems that patients with residual activity tolerate more phenylalanine in the diet than patients with no detectable activity. One infant with biochemical symptoms of classic PKU was found to have a normal phenylalanine hydroxylase activity.

\section{Speculation}

The variety of enzyme activities may reflect individual defects within the enzyme molecule. The clinical picture of PKU may not necessarily involve a defect of the phenylalanine hydroxylase in each 